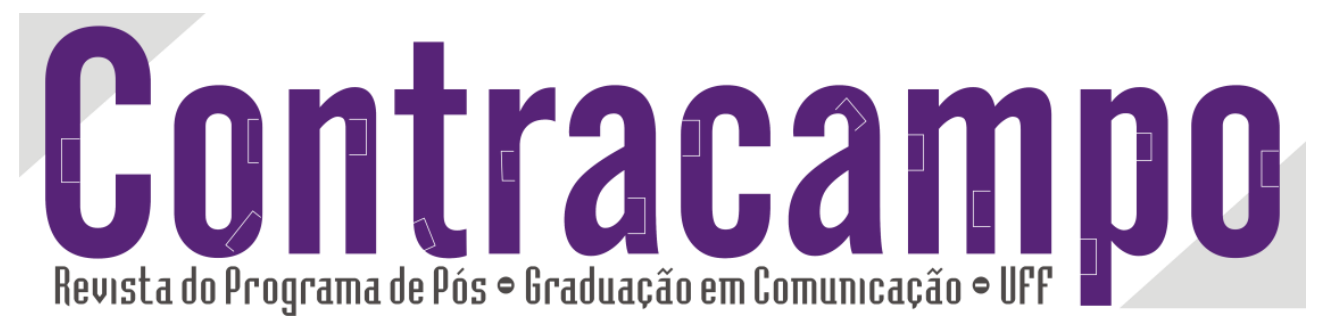

\title{
Tour de Force \\ 30 Rock Live Show e a metalinguagem do tempo direto
}

\author{
Tour de Force
}

30 Rock Live Show and metalanguage of direct time

Christian Hugo Pelegrini christian.pelegrini@gmail.com

Doutorando em Meios e Processos Audiovisuais pela ECA-USP, Professor da PUC de São Paulo e da Universidade São Judas Tadeu.

\section{PPGCOM $=$ UFF}

Ao citar este artigo, utilize a seguinte referência bibliográfica

PELEGRINI, Christian Hugo. Tour de Force: 30 Rock Live Show e a metalinguagem do tempo direto. In: Revista Contracampo, v. 24, n. 1, ed. julho, ano 2012. Niterói: Contracampo, 2012. Pags: 213-232.

\section{Edição 24//2012}

Temáticas diversas

Contracampo

Niterói (RJ), v. 24, n. 1, jul./2012.

e-ISSN 2238-2577

A Revista Contracampo é uma revista eletrônica do Programa de PósGraduação em Comunicação da Universidade Federal Fluminense e tem como objetivo contribuir para a reflexão crítica em torno do campo midiático, atuando como espaço de circulação da pesquisa e do pensamento acadêmico. 


\section{Resumo}

O artigo faz uma análise de 30 Rock Live Show, episódio da série americana transmitido em direto. Ao analisar o processo de transformação da estrutura formal de um single camera sitcom em um multicamera sitcom, condição necessária para a transmissão em direto, o artigo discute os aspectos formais dos sitcons americanos. Paralelamente, ao observar o processo da transposição de forma e seus desdobramentos em aspectos do texto final, o artigo registra em Live Show as marcas de seu modo de produção e de sua condição de performance metalinguística acerca da comédia, da TV e do tempo direto.

Palavras-chave: 30 Rock, sitcom, tempo direto.

\section{Abstract}

This paper analyses the 30 Rock Live Show, episode of the american serie broadcasted live. By analyzing the transformation of formal structures of a single camera sitcom in a multicamera sitcom, a necessary condition for a live broadcast, the paper discusses the formal aspects of American sitcons. At the same time, by observing the process of migration of form and its developments in aspects of final text, the paper records in Live Show the marks of its mode of production and its condition of metalinguistic performance about comedy, TV and live broadcasting Keywords: 30 Rock, sitcom, live broadcast. 
$\mathrm{E}$

m 14 de outubro de 2010, às 20 horas e trinta minutos (horário do Nova Iorque), a rede de TV norte-americana NBC exibiu o quarto episódio da quinta temporada do aclamado sitcom 30 Rock. Ao contrário do usual, o episódio exibido não fora prégravado, mas produzido "ao vivo" e em direto. Duas horas mais tarde, o feito foi repetido para regiões da Costa Oeste americana.

O que torna a exibição deste episódio (ou, diga-se: dos dois episódios) objeto deste artigo é o fato do programa ser, desde seu piloto, um single camera sitcom (ou sitcom de câmera única). Ao exibir 30 Rock "ao vivo" e em direto", a equipe executou um tour de force. Por um lado, deslocou o programa de seu modo de produção original, isto é, alterou a forma como são organizadas e executadas as etapas necessárias para que o programa chegue a sua forma final. Por outro, a transposição de modo de produção também acarretou uma mudança de linguagem, causando um retorno às convenções e práticas do sitcom clássico. Tais escolhas tornam-se, então, um discurso metalinguístico em que a linguagem da TV discute a linguagem da TV. 30 Rock Live Show é um programa de comédia em TV que mostra e discute como se faz um programa de comédia em TV; mais que isso, é um programa feito e transmitido em direto que discute a lógica de programas feitos e transmitidos em direto.

Ao realizar tal façanha, 30 Rock se coloca além de sua condição de episódio de série de TV. Acaba por se fazer como performance metalinguística da própria condição do texto televisual. Tal performance é, às vezes, intencional, compondo seu conteúdo em gags roteirizadas, intencionais e executadas conforme o ensaiado; em outros momentos, a performance é fruto da própria condição de programa transmitido em direto, com os elementos que simplesmente acontecem à revelia do roteiro e dos ensaios.

Este artigo propõe uma análise do processo de transposição do modo de produção e do retorno à forma clássica do sitcom para apontar nas apresentações de 30 Rock Live Show as marcas do tempo direto e da reflexão metalinguística empreendida pelo programa.

\footnotetext{
${ }^{1}$ A exibição "em direto" significa que o programa não é gravado e posteriormente exibido. Enquanto é encenado no estúdio, os espectadores o recebem em casa; simultaneamente.
} 
30 Rock

A premissa dramática de 30 Rock abre, desde seu episódio piloto, uma grande margem para metalinguagem ao mostrar os bastidores da produção de um programa de humor na TV. O "programa dentro do programa" TGS (acrônimo para The Girlie Show) é composto por sketches humorísticas e transmitido em direto (nos moldes do tradicional Saturday Night Live ${ }^{2}$ ). Embora 30 Rock tenha um número considerável de personagens, os enredos de cada episódio gravitam em torno de cinco personagens principais. A Redatora-Chefe do programa, Liz Lemon, é uma figura desiludida com sua incapacidade de se adequar aos padrões (tradicionalmente machistas) do que seja a mulher contemporânea e, ao mesmo tempo, gerenciar o caos de seu elenco e equipe de trabalho e ainda fazer o programa ir "ao ar" semanalmente e na hora marcada. A frustração de Lemon tem como contraparte Jack Donaghy, CEO da empresa que controla o canal (o próprio canal NBC), milionário e extremamente bem sucedido, com uma paulatina aproximação do estranho mundo da produção de televisão e uma crescente amizade com Lemon. O TGS tem como astros Jenna Maroney e Tracy Jordan. Ela, egoísta, hipersexuada e caricatamente burra. Ele, equivalente a Maroney em sua limitação intelectual, mulherengo e preguiçoso. Maroney é o estereótipo da loira burra; Jordan é o estereótipo do astro negro do hip hop. O último personagem é Kennedy Parcel, recepcionista do canal que, além de guiar turistas pelos estúdios onde se grava o $T G S$ e ser o "faz-tudo" para todos da equipe, tenta sobreviver ao ambiente insalubre de uma estação de TV com suas crenças e valores anacrônicos de típico caipira americano, uma figura moldada no estereótipo do white trash americano.

A comediante Tina Fey (que interpreta Lemon), criadora e produtora executiva de 30 Rock, faz uma versão paródica de sua função como Redatora-Chefe do antológico Saturday Night Live, onde atuou por nove anos. E ao longo das seis temporadas, as situações particulares, amorosas e domésticas dos personagens, se articularam com o sempre presente trabalho de produzir comédia em TV.

O episódio "Live Show" foi idealizado durante a leitura dramática de um roteiro, feita em palco, com renda revertida à equipe técnica que produz o programa e que sofria

\footnotetext{
${ }^{2}$ Saturday Night Live é um dos mais tradicionais programas de humor da TV americana. Composto por sketches que são transmitidas, em sua maioria, em direto nas noites de sábado (daí título). O programa é produzido desde 1975 e é um celeiro de comediantes e roteiristas. Ver TUETH, Michael V. Laughter in the Living Roon: Television Comedy and the American Home Audience, (capítulo 9)
} 
os efeitos da greve de roteiristas de 2007-2008 (Iizkoff, 2010). No episódio em questão, "Live Show", toda a metalinguagem ganha uma nova camada ao referir-se, em um programa feito e transmitido "direto", sobre fazer e transmitir um programa "direto".

\section{Modo de produção}

Por modo de produção, nos referimos às formas de organizar todas as etapas necessárias para que o conteúdo seja produzido e chegue ao espectador. Diferentes autores oferecem diferentes categorizações, contemplando em seu campo semântico aspectos diversos como o suporte em que é registrada a imagem (vídeo ou filme), a quantidade de câmeras (uma ou diversas), a forma de edição (se comutação dentre sinais simultâneos ou escolha de planos gravados) ou a relação temporal da transmissão (se gravado para exibição posterior ou transmitido em tempo direto). Embora tais categorias tentem conformar em um número limitado de categorias toda a amplitude de práticas de produção e excluindo detalhes e especificidades, podemos ainda assim recorrer às tentativas de categorização para melhor compreender o caso de 30 Rock Live Show.

Mittel (2010, p. 163) aponta que ao longo da história da televisão, três modos de produção principais se consolidaram como práticas da indústria e que trazemos aqui em sua nomenclatura conforme consta no original: Multi-Camera Live Studio Production, Single-Camera Telefilm Production e Multi-Camera Telefilm Studio Production. Butler (2003, 32\%), por sua vez, diferencia como modos de produção o single camera e o multicamera (excluindo o diferenciador da transmissão direta). Armes (1999, p. 131) oferece ainda a divisão de modos de produção de cinema, de televisão e de vídeo.

Considerando a falta de consenso, optamos por usar a classificação de Butler (2003, 32\%), uma vez que nela se baseia uma subcategorização do gênero sitcom (single camera sitcom e multicamera sitcom). Por adequação, traduzimos os modos para língua portuguesa: sitcom de câmera única e sitcom multicamera.

O modo multicamera está fortemente ligado à história dos sitcons e a seu mais emblemático exemplar: I Love Lucy. Em se tratando de uma produção gravada em multicamera, toda a mise-en-scène é preparada para ser capturada por três ou mais câmeras $^{3}$. A cena acontece integralmente em um estúdio, com uma dinâmica bastante

\footnotetext{
${ }^{3}$ Nos sitcons contemporâneos, usualmente são quatro câmeras (A,B,C e X).
} 
próxima da teatral. Todos contracenam, com sua movimentação e suas falas. As câmeras ficam dispostas em uma linha próxima da boca de cena, como a primeira fila do teatro. O que cada câmera faz é registrar um ângulo do que acontece. Assim, uma câmera grava um plano geral da cena; outra acompanha as falas de um dos personagens (ininterruptamente); outra câmera, ainda, acompanha as reações de outro personagens às falas do primeiro etc.

Nos primeiros anos da história da TV, o uso de multicameras para conteúdo de ficção demandava uma edição "ao vivo". Todas as câmeras convergiam para um comutador (um switcher), em que um diretor escolhia a cada momento qual era a câmera com uma imagem mais adequada para acompanhar a ação. Essa edição feita ao vivo era transmitida em tempo direto para os espectadores, ou seja, enquanto a cena acontece no estúdio e é editada na switcher, é vista pelos espectadores em casa (Mittel, 2010, p.166).

Ainda no começo da tecnologia de TV, a possibilidade de retenção e gravação do material editado estava limitada ao uso do kinescope: uma câmera de película que gravava o conteúdo diretamente de uma tela de TV. Tal possibilidade era bastante limitada em qualidade. A chegada do vídeo, na década de 50 permitiu a melhoria da gravação do material editado, gerando a prática do "ao vivo" em fita (live-to-tape). Gravar em video permitia que se registrasse o conteúdo com tanta qualidade quanto o que fora transmitido.

Uma variação do modo de produção multicâmera que se incorporou à histórica do gênero sitcom foi a introduzida na produção de I Love Lucy (1951). Este não foi o primeiro sitcom a usar três câmeras. Quase um ano antes, Amos $\tilde{n}$ Andy já era produzido com multicâmeras e editado "ao vivo" (Jacobson, 2010, p. 416) A inovação de I Love Lucy foi a de filmar integralmente cada uma das câmeras e depois editar o material bruto em uma forma final (Mittel, 2010, p. 171) Não cabe aqui entrar em detalhes acerca dos motivos que levaram a produção de I Love Lucy a adotar tal modo de produção ${ }^{4}$, mas ao fazê-lo, oferecia maior controle sobre a forma final do texto audiovisual e um incremento de qualidade de imagem sem precedentes para a época.

\footnotetext{
${ }^{4}$ Para tal, recomendamos DALTON, Mary \& LINDER, Laura. The sitcom reader:America viewed and skewed.Albany, New Your University Press, 2005 (p. 87).
} 
Assim, gravando cada uma das câmeras ininterruptamente e depois editando o material todo ${ }^{5}$, I Love Lucy estabeleceu uma forma de produzir seguida ate hoje por sitcons como Friends, Seinfeld, The Big Bang Theory e Two and a Half Men.

A produção com câmera única é muito mais complexa e sofisticada. É típico deste modo de produção que a mise en scene seja decupada em cada um dos planos que o diretor julgue adequado para contar a história. Neste aspecto, observa-se que a câmera única abre margem para uma variedade de enquadramentos e composições que devem pensados e decididos por um diretor.

Isso significa um tempo e dedicação para ajustar a iluminação, o posicionamento dos atores e marcações de movimento de câmera, a preparação da composição e uma longa série de providências para um único plano da cena. Cada tomada pode ser repetida até que o plano adquira a forma exata que o diretor procura. Os erros são descartados; a interpretação pode buscar nuances diferentes etc. Feito isso, ajusta-se tudo novamente para gravação de próximo plano da cena etc (Mittel, 2010, p.168).

E todo o trabalho para cada um dos planos passa, então, pelo crivo do editor, que decide, dentre todas as tomadas do mesmo plano, qual vai à edição final - quando esta efetivamente vai! Uma das marcas do modo de produção de produção em câmera única é que a realidade exibida na tela raramente acontece de maneira integral diante da câmera (Armes, 1999, 133). Ela é uma construção feita de fragmentos preparados um a um.

A edição posterior à gravação determina o que será efetivamente mostrado, suas relações causais e o tempo em que as ações transcorrerão. Como construção de fragmentos, a edição do material pode eliminar tomadas ruins e mostrar apenas a melhor parte de cada tomada. Os erros são eliminados e nunca chegam a exibição.

Também o tempo da narrativa é construído, não existindo previamente. A sucessão das ações está nas mãos do editor, que acelera ou desacelera. Os tempos mortos são removidos.

Essa parece ser a tônica de 30 Rock e dos sitcons de câmera única contemporâneos. Muitas gags (tanto verbais quanto visuais), sucedendo-se em ritmo extremamente acelerado.

\footnotetext{
${ }^{5}$ Conforme artigo de Leigh Allen para a "American Cinematographer" de janeiro de 1952, cada episódio de I Love Lucy utilizava 7500 pés de filme de 35mm. Ver OPPENHEIMER, Jess. Laughs, Luck - and Lucy: how I came to create the most popular sitcom of all time (Kindle Edition). 2009
} 
Explicados de forma sucinta, os modos de produção multicâmera e câmera única podem ainda levar a alguns equívocos. O primeiro equívoco é que tais modos são tão e unicamente uma enumeração da quantidade de câmeras. E isso não é verdade. Se tomarmos, por exemplo, a forma como o modo câmera única é aplicado no cinema, podemos observar casos de diretores que optam por usar, simultaneamente, mais de uma câmera (Butler, 2010, 64\%). Mesmo séries de TV como 24 (no Brasil, 24 Horas) e o próprio 30 Rock recorrem a mais de uma câmera simultaneamente. No entanto, ainda que cada tomada seja capturada por mais de um ângulo simultaneamente, persistem o planejamento de enquadramento e composição, as múltiplas tomadas de cada plano e a posterior construção do tempo diegético a partir de fragmentos.

Também é preciso evitar confusões acerca do tipo de suporte utilizado em cada modo de produção. Não há uma correspondência necessária entre os dois modos mencionados e a escolha de vídeo ou filme. A gravação em filme no modo multicâmera iniciado por I Love Lucy definiu uma prática seguida pela indústria ao longo de décadas. Programas como Friends, Seinfeld e Murphy Brown eram produzidos em multicâmera e com filme de $35 \mathrm{~mm}$. Da mesma forma, é possível encontrar sitcons multicâmera que usam vídeo -e.g. New Adventures of Old Christine, que usa câmeras Sony CineAlta F950 - (Butler, 2010, 72\%) ou mesmo programa de câmera única que optam pelo registro em vídeo - e.g. NYPD Blue.

\section{Rock Live Show}

Além da transposição de modo de produção, o que torna ainda mais especiais as duas transmissões de "Live Show" é o fato delas terem acontecido em tempo direto (vemos aqui em casa enquanto a ação acontece lá no estúdio). A equação aqui enquanto lá repete a dinâmica já mencionada da TV dos primeiros anos. Machado (1988, p. 70) faz um retrato primoroso da condição de se construir o texto no momento mesmo de sua transmissão. Enquanto a lógica do sitcom de câmera única remete a uma ética cinematográfica de eliminação do erro (e uma consequente estética da precisão), o conteúdo transmitido em tempo direto se desdobra para atenuar o imponderável, o equívoco, o deslize (Machado, 1988, p. 72 - 73). 
O primeiro aspecto que chama a atenção em "Live Show" é o fato das transmissões terem alcançado o status de evento midiático. Antes de serem um texto, constituíram-se explicitamente como performance comunicativa.

Antes de depender transitivamente de determinados conteúdos transmitidos, o sentido da transmissão reside então, reflexivamente, na própria performance da transmissão se fazendo. (LANDOWSKI in FECHINE, 2008, p. 8)

Ainda que a referência de Landowski seja do conteúdo jornalístico, mostra-se mais singular o fato de "Live Show" se inserir em um contexto de ficção seriada, oferecendo ao espectador a experiência do texto em ato (Fechine, 2008, p.10), que acontece uma única vez em sua forma original, como uma apresentação teatral ou uma performance de jazz.

Como já foi mencionado, por muitos anos a transmissão era feita dessa forma ("ao vivo" e direto). No entanto, tão logo os programas de ficção passaram a ser produzidos em filme e, poucos anos depois, em vídeo, as transmissões diretas se tornaram escassas e dedicadas a eventos com um tempo próprio, alheio ao da TV. Não só a complexificação narrativa e os aspectos práticos de produção apontavam para a produção gravada, mas a crescente exploração comercial em syndication tornava imprescindível que os conteúdos existissem em sua forma gravada (Mittel, 2010, p.170). Assim, ao tornar-se exceção nas práticas da indústria, a transmissão direta passou a ser vista como um evento especial no contexto da ficção televisual.

A história da TV americana é plena de exemplos dessa natureza. De dramas hospitalares $(E R)$ a políticos (West Wing) ou mesmo dentre diversos sitcons (Drew Carrey Show, Will \& Grace), pode-se encontrar muitos exemplos de transmissão direta (Mittel, 2010, p.167). Tais eventos começam a acontecer antes de sua transmissão, uma vez que são alardeados intensamente pelos canais de comunicação (chamadas na própria $\mathrm{TV}$, reportagens em mídia especializada impressa e, no contexto atual, na força e onipresença da internet).

Desta forma, episódios como "Live Show" constroem uma trama de relações intertextuais com textos secundários que, por sua vez, dispara uma constelação de textos 
terciários $^{6}$ (Fiske, 2011, p. 110). Tais relações convergem e aumentam a força do evento quando este acontece. Ainda que o episódio possa ser visto posteriormente (em gravações, reprises ou internet), ver o episódio no exato instante em que ele acontece marca um retorno à experiência simultânea e ao paradigma do fluxo que marcou a inserção da TV como forma cultural por décadas.

Devido ao fuso entre a Costa Leste e a Oeste do EUA, uma transmissão direta só faria sentido se fosse direta para ambos os públicos. Um morador da Costa Oeste (duas horas a menos) estaria fadado a ver o programa gravado se ele não fosse apresentado duas vezes; para a Costa Leste seria um evento, para a Costa Oeste seria uma exibição gravada. Por outro lado, em um ambiente de convergência digital, as redes precisam garantir que os espectadores assistirão ao programa na TV, e não buscando-o na internet. Daí a importância de fazer valer a pena esperar pela exibição de 30 Rock "Live Show" na TV para os espectadores da costa Oeste, tornando-o singular em relação à primeira exibição. Em outras palavras, era imprescindível fazer com que ambos os públicos assistissem ao mesmo episódio, mas cada um assistisse um episódio único.

Assim, o 30 Rock "Live Show" da Costa Leste (apresentado antes) e o 30 Rock "Live Show" da Costa Oeste (apresentado depois) tinham as mesmas linhas gerais de enredo, mas com detalhes que tornavam cada performance única. Cenas foram modificadas, com gags diferentes. Na abertura do programa, o tema musical foi cantado ao vivo nas duas vezes, mas com intérpretes diferentes (na Costa Leste, cantado pela atriz Jane Krakowski; na Costa Oeste, pelo ator Cheyenne Jackson). A letra do tema foi alterada nas duas vezes. Enquanto na primeira exibição questionava sobre o porquê de um programa direto, a segunda letra fazia menção explícita à região do Pacífico (Buchanan, 2010). Em uma cena que representava um intervalo comercial do programa $T G S$, uma campanha incentivando a doação de mãos (!) mostrava um homem branco com uma mão transplantada. Na primeira versão (Costa Oeste), a mão é negra; na segunda versão (Costa Leste), a mão é feminina. Diversas “diferenças” foram inseridas nas versões para torná-las singulares.

Há, no entanto, uma série de diferenças entre as versões que não são parte de seu conteúdo, mas fruto de sua própria condição de performance "ao vivo". Logo na

\footnotetext{
${ }^{6}$ Usamos aqui as categorias propostas por Fiske, em que os textos secundários são os produzidos pela própria mídia, enquanto os terciários são os produzidos pelos espectadores (e que ganham nova dimensão em tempos de redes sociais).
} 
abertura do programa, no primeiro plano, o personagem de Jack Donaghy observa em um monitor os preparativos para a abertura do $T G S$ da noite. Uma voz no sistema de som do estúdio chama a atenção de todos para a abertura do programa. Jack desliga o monitor. A personagem Liz Lemon entra em sua sala. Na exibição da Costa Leste, o personagem demora quase quatro segundos para desligar o monitor; nesse meio tempo permanece de costas para a câmera sem que nada aconteça. Entre o fim da fala do sistema de alto falantes e a próxima fala (da personagem Liz Lemon), há um hiato de 6,3 segundos (um silêncio gigantesco para a TV e para o ritmo do próprio programa). $\mathrm{Na}$ versão da Costa Oeste, este tempo cai 2,8 segundos. Na versão da Costa Leste, Lemon bate à porta e já a abre. O som é fraco e quase não é percebido. Na versão da Costa Oeste, ele é claro e "preenche" o vazio no intervalo de 2,8 segundos. Também o sistema de alto falantes é bem menos audível na primeira transmissão que na segunda.

Em uma cena, a personagem Lemon explica ao personagem Jordan que ele não deve "errar" sua interpretação de propósito, mesmo sabendo que a audiência adora quando coisas saem errado. Neste exato instante, um quadro pendurado no fundo do cenário pende ruidosamente para o lado. Este fato é parte do conteúdo da cena e acontece bem no meio da fala: "audiences love it when something goes wrong (quadro pende) but we don't do that gig”. No entanto, na exibição da Costa Leste, o quadro leva mais tempo para pender. Assim, uma frase que deveria ser ininterrupta, acaba ficando com uma pausa pouco natural. Na exibição da Costa Oeste, a deixa é perfeita.

O quadro que pende durante uma explicação sobre o prazer que o publico sente ao ver algo dar errado em um programa de TV direto é parte da metalinguagem proposta pelo episódio. $\mathrm{O}$ atraso do quadro na primeira exibição não é parte do conteúdo, mas resultado de sua forma. Idem para a longa pausa do personagem Donaghy na primeira cena. Outros "erros" acontecem ao longo das exibições e tornam-se elementos que reforçam a diferenciação entre as versões das costas Leste e Oeste.

A sujeição ao incontrolável do tempo direto também aparece em um elemento que marca o retorno de "Live Show" às convenções do sitcom clássico. Desde os primeiros títulos do gênero, é comum a participação da plateia que assiste à gravação na forma de risadas, aplausos ou outras formas de entusiasmo. O "riso enlatado" tem origem nos programas de rádio dos anos 30 (Berciano,1999, p. 39). Se no início era solicitado aos 
presentes que mantivessem silêncio, aos poucos percebeu-se que o riso no estúdio levava ao riso dos ouvintes em casa.

Com o tempo, a participação da plateia começou a ser domesticada pelas práticas de produção. Por um lado, as deixas para a participação do público começaram a ser marcadas por grandes avisos luminosos colocados acima da plateia e que piscam nos momentos adequados (Butler, 2002, 36\%). Além disso, a inserção da participação passou a ser editada na versão para veiculação, editando-se a entrada, duração e intensidade do áudio da plateia em uma laught track (uma "pista de riso" ou claque). Tal operação, chamada de sweetening, permite aproveitar os efeitos da dinâmica, mas mantendo o controle sobre ela.

Tal controle não foi possível em 30 Rock "Live Show" uma vez que não havia a edição posterior à encenação. Assim, alguns trechos de riso ficaram muito fortes e longos. Outros trechos, no entanto, simplesmente ficaram vazios. Havia a pausa dos atores para o riso, mas este é tímido (e.g. na fala: Lemon: "It's a pretty big birthday", Jonathan: “Oh! Are you turning a thousand?”).

"Live Show" também marca o retorno ao modo de produção multicâmera (em oposição ao modo original do programa, que é câmera única). Tal alteração era imperativa diante da decisão de se fazer um episódio direto. O processo de conversão pode ser notado então não apenas pelas marcas do multicâmera, mas também pelo cuidado ao se produzir algo para funcionar "de primeira" (uma vez que é direto). Via de regra, quando consideramos a gravação de sitcons em modo multicâmera, devemos lembrar que eles podem, sempre, assimilar erros e regravar cenas que não funcionaram. Certos títulos chegavam a assumir isso como um diretriz de produção: sempre gravar cada cena duas vezes (Butler, 2010, 68\%).

$\mathrm{O}$ uso de multicâmeras em direto alterou diversos aspectos da videografia de 30 Rock. O que seria natural acontecer com os personagens dispostos um de frente ao outro, acaba acontecendo com os personagens levemente oblíquos em relação ao eixo óptico da câmera central; como que voltados para o público. Nos planos que alternam com contra-plano, tal impressão fica atenuada pelo próprio posicionamento da câmera, mas nos planos que enquadram os dois interlocutores, tal disposição fica mais evidente. 


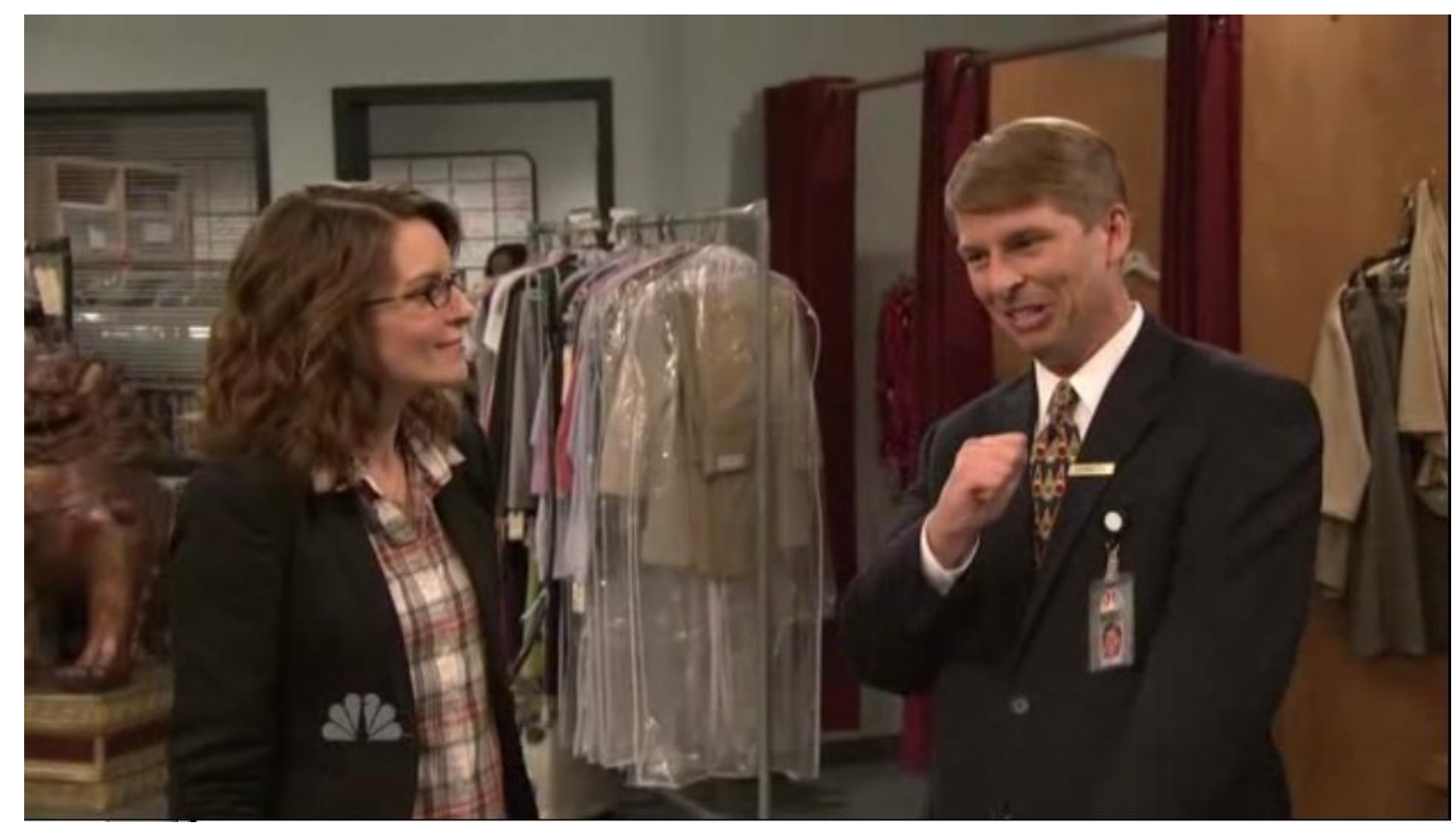

Fig. 01. Personagens em disposição oblíqua.

A razão do posicionamento oblíquo é o fato do enquadramento em multicâmera ser mais limitado. As câmeras, em geral, precisam ficar antes da (inexistente) quarta parede. Isso diminui sua capacidade de compor plano/ contra-plano a partir da perspectiva exata dos interlocutores. Diante disso, o mais usual é que tais enquadramentos aconteçam pela lateral dos personagens, mostrando seu interlocutor de forma obliqua. Isso não é um problema para sitcons de multicâmera, telenovelas e soapoperas. No entanto, nestas situações, é a câmera que se posiciona obliquamente. Isso se ratifica nos enquadramentos em que os interlocutores aparecem juntos, frente a frente: ao voltar-se levemente para a quarta parede, os atores "facilitam" o trabalho dos operadores de câmera. Em "Live Show", a necessidade de garantir que o enquadramento funcionará na primeira (e única) tentativa coloca os atores em uma posição pouco usual para situações de diálogo.

Tal necessidade de acertar "de primeira" também explica uma tendência em "Live Show" de se produzir enquadramentos pouco precisos. A proporção dos personagens no quadro às vezes é menor do que seria o convencional para uma cena de diálogo emocional. A demanda por enquadrar sucessivos atores com diferença de altura acentuada exige da parte dos operadores de câmera uma perícia singular. Assim, é comum ver composições com excesso de teto ou personagens com espaço de sobra no quadro. Também se observam enquadramentos que acabam ficando sem o espaço a 


\section{Contracampo}

frente do personagem (uma composição desequilibrada pelos princípios correntes).

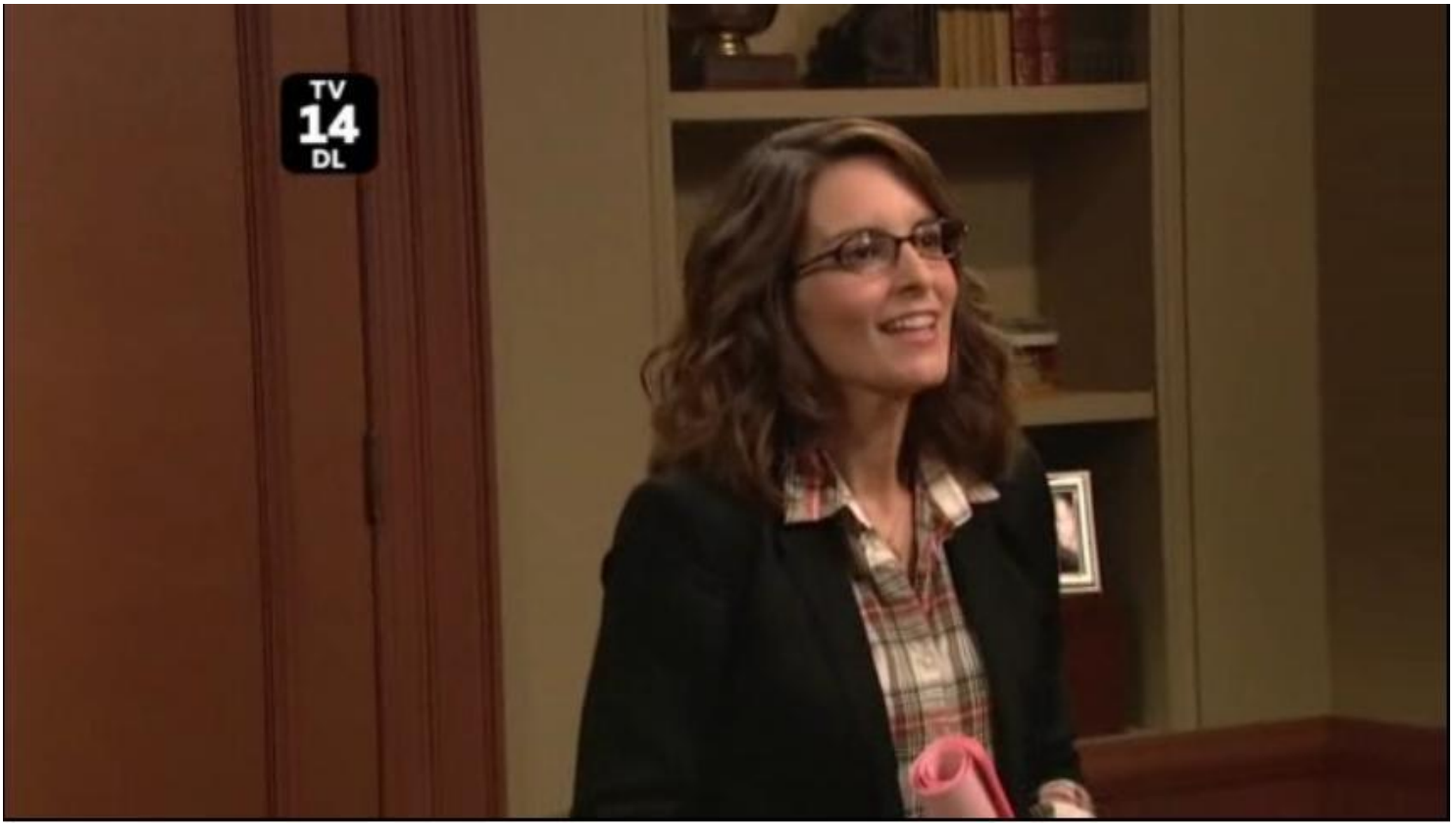

Fig. 02. Enquadramentos "defeituosos".

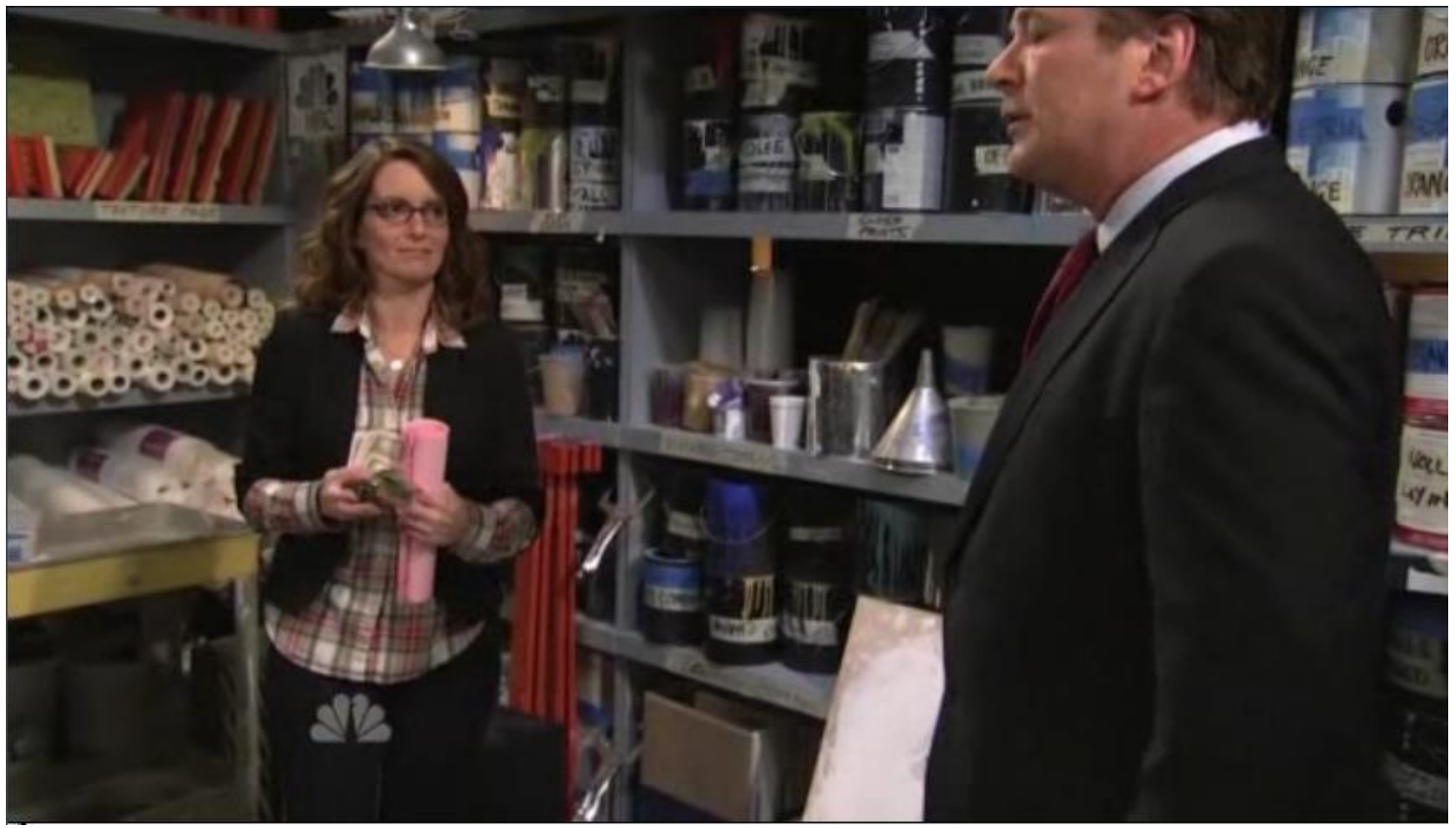

Fig. 03. Enquadramentos que "mutilam" os personagens.

A textura da imagem se modifica consideravelmente. Em sua forma original, 30 Rock é visualmente tão sofisticado quanto um filme de longa metragem. Na preparação de cada cena, todos os cuidados são tomados para dar à imagem a aparência ótima. Ao 
analisar o processo de trabalho de Vanja Cernjul, Diretor de Fotografia de 30 Rock, Silberg salienta o processo de preparar a luz do escritório de Jack Donaghy:

\begin{abstract}
Este espaço oferece a oportunidade de alterar a luz baseado na hora do dia e a abordagem que Cernjul faz do espaço ajuda a compensar a diferença significativa de tom de pele dos astros. 'Tina é bem pálida e Alec é bem bronzeado' ele observa, acrescentando que a questão primária não é exposição, mas a composição de cor realista para cada ator. (...) 'Tentamos resolver com luz, assim eles não tem que usar maquiagem pesada', ele [Cernjul] explica. (SILBERG, 2008, p.65)
\end{abstract}

Em se tratando de multicâmera e principalmente em transmissão direta, a direção de fotografia de cada plano não pode ser pensada com calma e sofisticação como no modo câmera única. Absolutamente tudo precisa estar plenamente "capturável" pela câmera. A luz, usualmente rica em expressividade, compondo com claros e escuros significantes, torna-se a usual high light, iluminando a tudo e a todos igualmente. $\mathrm{O}$ espaço cênico é livre de bloqueios (tanto ao movimento das câmeras, quanto as imagens). Também é consideravelmente raso, acentuando a tendência às composições transversais ou, no dizer de Bordwell (apud Butler, 2010, 70\%), planimétricas "como roupas dispostas em um varal". Não há externas. O cenário é claramente em estúdio e não permite mostrar o teto (inexistente em um estúdio). Assim, restringe-se também contra-plongés ou câmeras mais baixas.

É interessante notar que, enquanto 30 Rock "Live Show" aceitou declaradamente mudar suas características estéticas em função da transposição de modo de produção e de sua condição de performance, houve, por outro lado, uma tentativa de guardar aspectos de sua forma original que demandaram soluções de linguagem um tanto criativas. Em sua forma original, 30 Rock faz constante uso de inserts no meio do fluxo narrativo para mostrar em flashbacks fatos a que os personagens fazem referência em suas falas (marca registrada do programa e identificado com um fake wipe lateral e um efeito sonoro de whoosh). Tal recurso é bastante comum em sitcons de câmera única.

Tal traço nos sitcons de câmera única se deve as possibilidades de edição permitidas pela forma de produção (é montagem como no cinema). No caso de "Live Show", apesar da mudança para um modo de produção que dificulta o uso de tais inserts, 30 Rock consegue a façanha de manter-se ainda reconhecível, guardando seus estilemas mais peculiares. 
A solução encontrada para os flashbaks dos personagens, quando estes se lembram de suas próprias experiências, foram fake wipes ${ }^{7}$ que levavam a outra cena (do passado e em outro espaço). $\mathrm{Na}$ cena de insert, atores diferentes interpretam os mesmos personagens da cena de origem. Para o público, ver o insert com a atriz Julia Louise Dreyfuss interpretando Liz Lemon não interfere negativamente na fruição. Aliás, o uso de atrizes diferentes para a mesma personagem confere ao texto um requinte de virtuosismo narrativo que é não só percebido, mas apreciado pelo público contemporâneo (Mittel, 2006, p.32).

Talvez a mudança mais sensível em "Live Show" seja a mudança em seu ritmo. Mesmo considerando que em sua forma original a maior parte das gags é verbal, há ainda muitas possibilidades de explorar o humor visual. E o programa o faz. Tudo isso em um ritmo extremamente acelerado (Van Deer Werff, 2010). No entanto, embora a produção em single câmera abra margem para se explorar gags visuais, a demanda pela frequência nas gags ainda coloca muita responsabilidade na construção dos diálogos. Para o showrunner do programa, Robert Carlock (apud Bolonick, 2011), há uma clara resposta do público à alta densidade cômica do programa. Pois ao optar por produzir com platéia em estúdio e assumir a claque, os produtores de 30 Rock também desaceleraram o ritmo do programa. A necessidade de deixar espaços entre as falas para que a platéia pudesse responder às gags reduziu o tempo total de fala dos personagens. Além disso, em uma transmissão direta, não há como reduzir o "ar" dos diálogos (o tempo entre os turnos de fala).

Como as gags do programa são predominantemente verbais, o número de gags foi muito menor que o usual. Quando comparamos "Live Show" com o episódio anterior, "Let’s Stay Together", há uma sensível diminuição de fala. Em "Live Show", na versão da Costa Oeste, há aproximadamente 2900 palavras. Em "Let's Stay Together”, que mantém sua forma original, há aproximadamente 3220 palavras.

Isso diminuiu o andamento usual do programa. Se compararmos "Live Show" com o episódio anterior perceberemos quantitativamente a mudança. Analisados os

\footnotetext{
${ }^{7}$ A despeito da inventividade da solução encontrada para manter o traço de estilo do programa no uso do insert, sua condição de transmissão direta acabou por levar a mais erro: durante o segundo fake wipe do episódio da Costa Leste, o que deveria ser a junção de dois "chicotes" (uma pan para a direita que sai da primeira cena e uma pan para direita que chega na segunda cena) não foi cortada a tempo. O resultado e o primeiro chicote mostrando um operador de câmera que estava ao lado.
} 
episódios com o sistema cinemetrics ${ }^{8}$, observa-se em "Let's Stay Together" uma duração média dos planos (Average Shoot Lengh ou ASL) de 2,6", com alguns planos inferiores a 15 frames ou meio segundo.

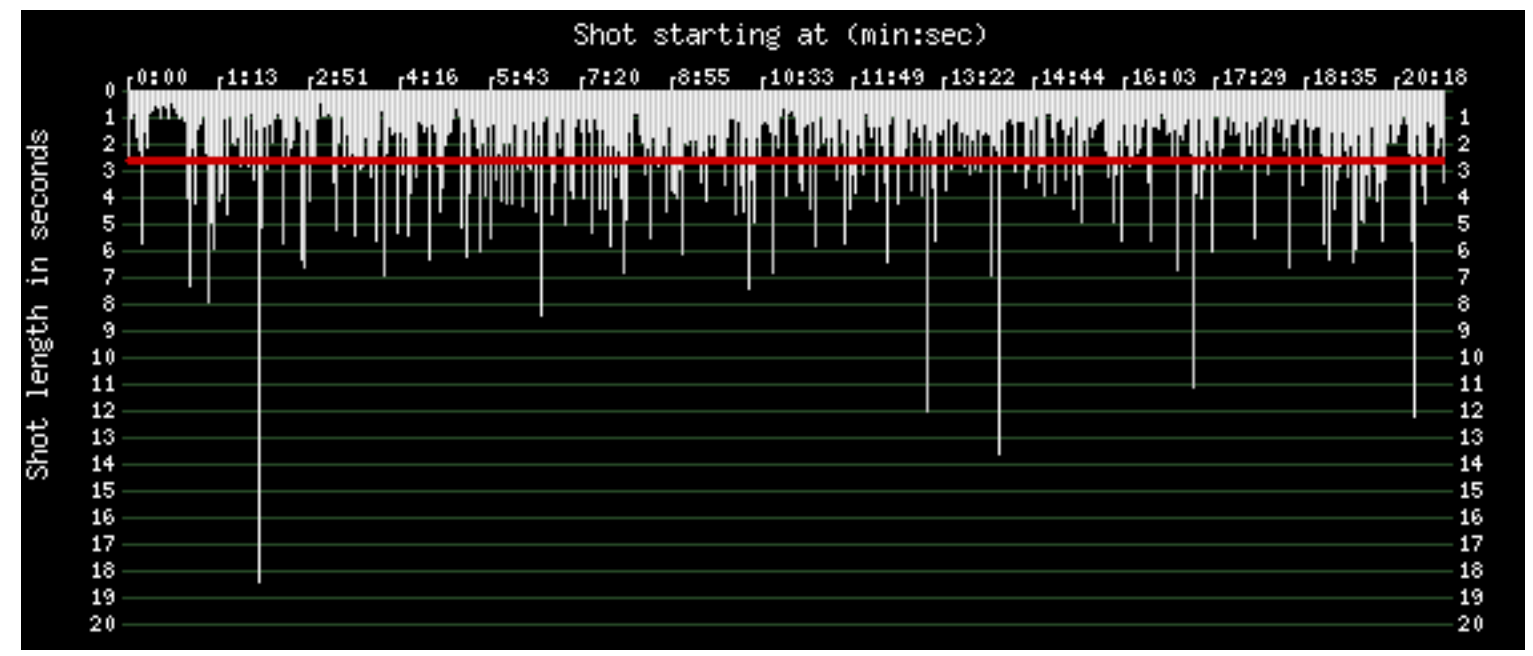

Fig. 04. Gráfico do sistema Cinemetrics para o episódio "Let’s Stay Together”, de 30 Rock.

Quando analisamos "Live Show" pelo mesmo método, obtemos uma duração média dos planos de 6,1” (sem planos inferiores a 1 segundo). Há, ainda, uma certa aceleração (bastante tênue) ao longo do episódio. "Let’s Stay Together" é extremamente regular em seu ritmo.

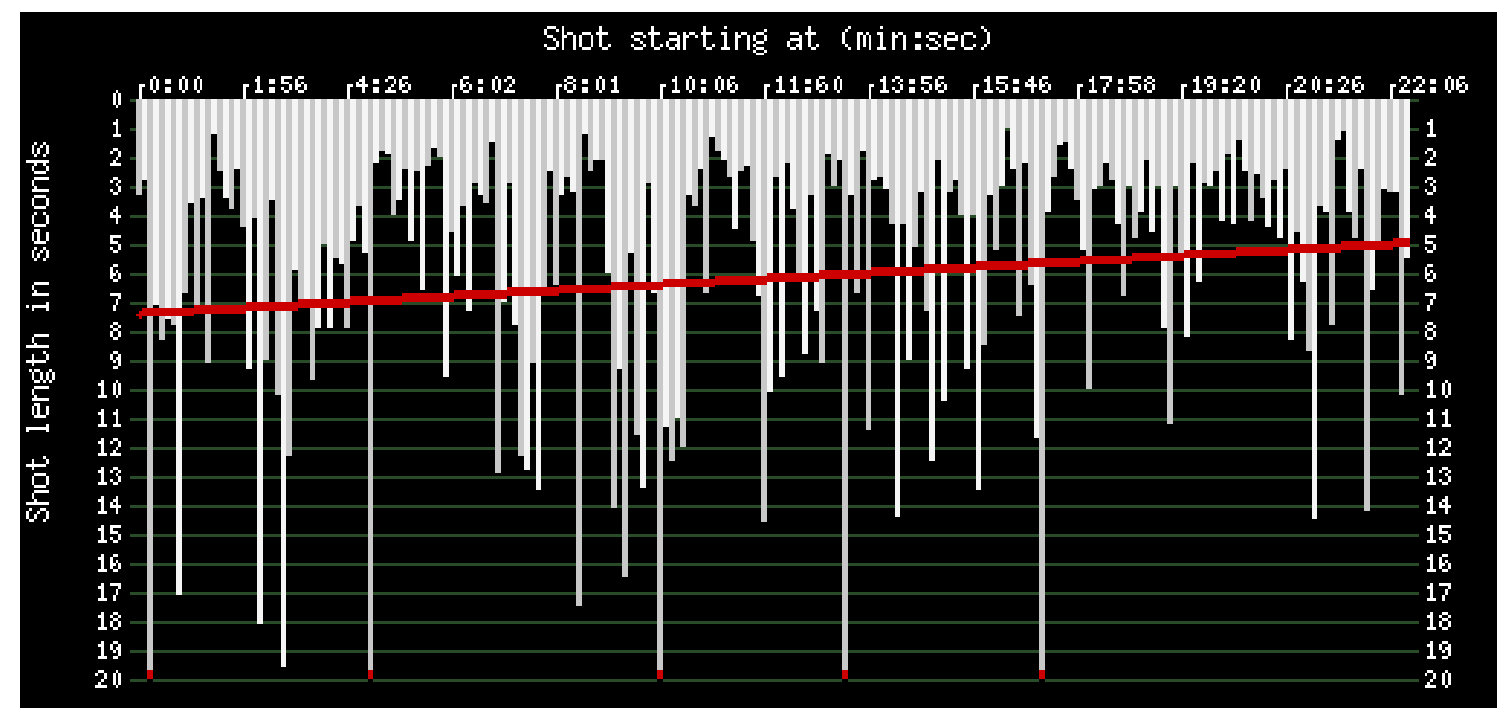

Fig. 05. Gráfico do sistema Cinemetrics para o episódio “Live Show”(versão Leste), de 30 Rock.

\footnotetext{
${ }^{8}$ Cinemetrics é um sistema de banco de dados de medição de recursos de linguagem cinematográfica. Em nosso estudo, usamos para avaliar duração média de planos. Disponível em www.cinemetrics.lv/index.php .
} 
Saliente-se, ainda, que o enredo sofre ação direta da questão temporal ao aproximar o tempo diegético do tempo real. O episódio "Live Show" se inicia pouco antes de um episódio do TGS (o programa humorístico produzido dentro de 30 Rock) e ambos acabam praticamente juntos. Ao contrário dos episódios regulares, em que há mais elipses (logo, mais tempo diegético), "Live Show" mostra menos tempo do universo da história, demandando um enredo onde menos eventos aconteçam.

Ao optar pela transmissão direta, 30 Rock também afetou sua dimensão sonora. Da mesma forma que o trabalho de câmera nos episódios regulares tem certa sofisticação, a edição dos pontos de escuta e a variação das falas dos personagens lançam mão de dinâmicas sonoras que enriquecem a narrativa. Na transmissão direta, não há o "interromper" ou o "corrigir". Assim, em "Live Show", os personagens perdem a variação de dinâmica na impostação da voz. Gritos e sussurros tornam-se muito parecidos. E muito fortes, para garantir que os microfones captarão os sons e que todos em casa receberão a fala do personagem.

\section{Considerações Finais}

São muitas as referências que o próprio programa faz ao modo de produção. Há o personagem que decide errar a interpretação durante a transmissão direta do programa $T G S$, sair do personagem e cair na gargalhada por saber que o público acha engraçado; há afirmação de que o público adora quando algo dá errado no exato momento em que um pôster despenca da parede; a auto-referência de anunciar uma abertura fria ${ }^{9}$ (do programa $T G S$ ) no exato momento em que começa a abertura fria de 30 Rock. Há mesmo a moldura narrativa do episódio, em que o personagem Jack Donaghy, brincando com o estereótipo do irlandês beberrão, decide parar de beber (sendo sua abstinência a provável causa de "tudo estar estranho"). Ao final do episódio, após um a gole de bebida, a imagem volta à sua textura e luz originais e ao seu enquadramento típico da produção em câmera única.

A auto-referência não é algo tão inovador no universo televisual. Desde as primeiras discussões de Umberto Eco sobre a neo TV tem-se isso como traço

\footnotetext{
${ }^{9}$ Abertura Fria (Cold Opening) é o trecho do programa exibido antes da vinheta de abertura (e, usualmente, logo após o final do programa anterior). A função da Abertura Fria é "pegar" o público do programa anterior e manter o índice de audiência.
} 
característico do próprio meio (1984: 186). No entanto, em 30 Rock "Live Show" ela acontece com ares de uma proeza circense, um requinte de virtuosismo técnico. Ainda que seja possível apontar falhas na realização do programa (enquadramentos tremidos, ritmo mais lento etc), é essencial lembrar que tais características são intrínsecas ao modo de produção, fazendo com que nos questionemos sobre o quanto são, de fato, falhas ou meros traços do modo de produção. 30 Rock oferece, assim, uma proposta de diálogo acerca da linguagem televisual que vai além de seu conteúdo imediato, assimilando na própria construção textual - reafirmando, mais uma vez, "um certo valor de enunciado à própria enunciação" (Fechine, 2008, 16).

\section{Referências bibliográficas}

ARMES, Roy. On Video: o significado do vídeo nos meios de comunicação. São Paulo: Ed. Summus, 1999.

BERCIANO, Rosa A. La comedia enlatada: De Lucille Ball a Los Simpsons. Barcelona: GEDISA, 1999.

BOLONICK, Kera. "The Showrunner Transcript: 30 Rock's Robert Carlock on Working on Joey and His Dedication to Joke Density" in Vulture, 16/05/2011, disponível em http://www.vulture.com/2011/05/robert_carlock_showrunner_tran.html, acessado em 15 de novembro de 2011.

BUCHANAN, Kyle. "The 17 Differences Between 30 Rock's East Coast and West Coast Live Episodes" in $\quad$ Vulture, 15/10/10. Disponível em http://nymag.com/daily/entertainment/2010/10/the_17_differences_between_30.html, acessado em 15 de julho de 2011.

BUTLER, Jeremy G. Television: Critical Methods and Applications (Kindle Edition). London, Taylor \& Francis, 2002.

Television Style (Kindle Edition). New York: Routledge, 2010.

ECO, Umberto. Viagem na irrealidade cotidiana. Rio de Janeiro, Ed. Nova Fronteira, 1984.

FECHINE, Yvana. Televisão e Presença: uma abordagem semiótica da transmissão direta. São Paulo: Estação das Letras e Cores, 2008.

FISKE, John. Television Culture. New York: Routledge, 2011.

ITZKOFF, Dave. "Urban Fervor: '30 Rock' Shares Details of Its Live Episode" in New York Times. New York, 12 outubro de 2010, disponível em http://artsbeat.blogs.nytimes.com/2010/10/12/urban-fervor-30-rock-shares-details-of-its-liveepisode/?scp=1\&sq=Urban\%20Fervor:\%20\%E2\%80\%9830\%20Rock\%E2\%80\%99\%20Shares \%20Details\%20of\%20Its\%20Live\%20Episode\&st=cse, acessado em 15 de julho de 2011. 
JACOBSON, Mitch. Mastering Multicamera Techniques: from preproduction to editing and deliverables. Oxford: Focal Press, 2010.

MACHADO, Arlindo. A Arte do Vídeo. São Paulo, Ed. Brasiliense, 1988.

MITTEL, Jason. "Narrative Complexity in Contemporary American Television" in The Velvet Light Trap, Number 58, fall 2006.Austin: University of Texas Press, 2006

Television and American Culture. New York: Osford University Press, 2010.

SILBERG, Jon. "Laugh Factory" in American Cinematography 89, n 07 Julho de 2008.

VAN DEER WERFF, Todd. "Live Show" in The A.V. Club, 15 de outubro de 2010, disponível em http://www.avclub.com/articles/live-show,46199, acessado em 16 de julho de 2011. 